\title{
CONCEPTUAL DIRECTIONS IN ORGANIZATION OF MEDICAL ASSISTANCE FOR CHILDREN IN THE CONDITIONS OF EDUCATION
}

D0I: 10.36740/WLek202006108

\author{
Georgii M. Danylenko ${ }^{1,2}$, Tetiana V. Peresypkina ${ }^{1,2}$, Antonina I. Butenko ${ }^{1,2}$, Anna M. Peresypkina ${ }^{2}$, \\ Halyna I. Holubnycha ${ }^{1,2}$, Andrii M. Zinchuk ${ }^{1,2}$, Olha G. Zinchuk ${ }^{2}$ \\ 'STATE INSTITUTION “INSTITUTE FOR CHILDREN AND ADOLESCENTS HEALTH CARE OF THE NATIONAL ACADEMY OF MEDICAL SCIENCES OF UKRAINE", \\ KHARKIV, UKRAINE \\ 2V.N. KARAZIN KHARKIV NATIONAL UNIVERSITY, KHARKIV, UKRAINE
}

\begin{abstract}
The aim of this work is: to define the Conceptual model of medical provision of children in educational institutions in modern conditions.

Materials and methods: analysis of data from a longitudinal study of children's health; questionnaire of parents, teachers, heads of educational institutions on the volume of medical support for students; questioning students' lifestyle and social determinants of health.

Results: According to the study has determined the medical and social determinants which negative affect on health status of school age childrens; detected the most appropriate types of of school health services which based on the parents, medical and teachers opinion. The important also is monitoring of health status of children for develop of prevent measure for improove health status and forming of healthy lifestyle behavioral. Problematic issues to be addressed include: improving the legal framework on the competences and volumes of health care for pupils in educational institutions; material equipment; setting up a system for monitoring and analyzing the health status of students and educational groups, identifying health risk factors; establishing a continuous multimodal health-oriented system of student-oriented youth behavior.

Conclusions: The health status of students and the level of health-oriented behavior, the reform of the medical sector require introduction of an effective system of medical support for students of organized groups, improving the system of preventive care for students, parents, which is presented in the Conceptual model.
\end{abstract}

KEY WORDS: school health services, medical care, health status

Wiad Lek. 2020;73(6):1124-1128

\section{INTRODUCTION}

The hallmarks of today are the reform of the health care and education systems.

The main changes in the general secondary education system concern the structure of the educational process, the level of educational load, the introduction of a profile education in high school, as well as the introduction of innovative pedagogical technologies, the introduction of an inclusive educational system for children with special needs. All this is happening on a background of reduction of programs that prevent the development and spread of noncommunicable diseases, as well as programs that form health-forming behavior among students; increasing number of children with addictive behaviors and the spread of nervous system diseases, mental and behavioral disorders confirms the imperfection of medico-psychological and pedagogical support of schoolchildren.

Health care reform has touched many aspects of health care, including the health care system of children in organized groups. Preschool departments in pediatric clinics were abolished in accordance with the conditions of reforming the primary care unit. Today, the provision of medical care to children in educational settings is predominantly provided by a nurse, and in case if number of students is more than one thousand, by both nurse and a doctor who have become full-time units of educational institutions. Mainly, educational institutions do not yet have a license to conduct medical practice, which has led to changes in the types and volumes of medical provision for schoolchildren.

With primary care reform, the volume of patients under the care of a pediatrician or family physician has increased. Many school-age children attend educational institutions not quite near their homes, which makes it impossible to take preventative measures on the level of educational institutions due to the lack of timely monitoring of health of the educational groups. Mean while, educational institutions have a strong potential for influencing health-forming behavior.

Therefore, in order to improve the health of children in educational institutions, prophylaxises and prevention spread of noncommunicable diseases, and to shape the health-oriented behavior of schoolchildren, it is necessary to develop a cross-sectoral approach to health carefor children in educational settings.

\section{THE AIM}

The aim of this work is to substantiate the concept of health care for children in educational institutions in the context 
of reforming the health care system and development of the preventive medicine system.

\section{MATERIALS AND METHODS}

Analysis of longitudinal monitoring of the state of health of children (grades 1 through 9), data of parents questionnaire (251), teachers (87), heads of educational institutions (322) and medical professionals (55) on the expedient and possible volumes of medical care for children in terms of educational institutions; a survey of students (821) on lifestyle, social determinants, and health behaviors.

\section{RESULTS AND DISCUSSION}

The problem of health formation is multifaceted. Among the factors that determine human health, leading places are those of lifestyle, behavior and health care. When planning preventive measures, it is important to know exactly what factors are being targeted, reducing the impact of what factors or indicators need to be achieved. From this point of view, information about real health is important.

In Ukraine, the main institution that conducts cumulation and analysis of statistical information on health status, provision of health care and health resources is the State Medical Center of the Ministry of Health of Ukraine [1].

Today, due to medical sector reform, some statistical forms for determining the prevalence and structure of diseases among different segments of the population have lost their validity, therefore, a more complete analysis of the health status of the child population of Ukraine can be carried out on the basis of data from the Center for Medical Statistics for 2017 only.

Thus, in the period 2001-2017 yy., in Ukraine the prevalence of diseases changed among children 7-14 years by $2,4 \%$, among adolescents (15-17 years) has increased by $46,6 \%$, (from 1485,7 to $2177,7 \%$ ).

The statistics of the average Ukrainian or regional prevalence rates of diseases make it possible to compare them, to determine the most common classes of diseases according to the ages of 7-14 and 15-17 years, to estimate the dynamics of changes. However, this information is rather important for planning strategic directions. But for targeted prevention initiatives it is advisable to determine the dynamics of changes in the health status of children in each educational institution and educationalgroup. Given the potential of a powerful influence of the educational institution, this is logical and appropriate.

Health monitoring, pathological analysis, in particular, helps to identify "critical" periods for the deterioration of students' health, periods of disease manifestation, which provides ample and effective opportunities for preventive work. Thus, an analysis of the health status of students in one of the Kharkiv high schools during the period of their education from the first to the ninth grade showed that the pathological indices are wavy. The increase occurred in the third grade (from 2308,2 to $2860,5 \%$, $\mathrm{p}<0,05$ ), mostly among boys. The stage of completion of elementary school was characterized by the stabilization of adaptation processes, which was manifested by the positive dynamics in the health status of the fourth grade students - the stabilization of the general pathological lesions (PL) to $2715,2 \%$ ( $p>0,05)$ during the schoolyear and improving indexes (up to $2464,3 \%, p<0,05$ ) during the summer vacation, which was also most pronounced among boys. Upon further observation, at the elementary school stage, the indicators of general PL increased up to $2766,4 \%$ o during fith grade studying, among both girls and boys $(\mathrm{p}<0,05)$, with maximal PL indexeson the beggining of sixth grade studing (2900,0\% - among boys, 2880,6\% - among gils). The following is the dynamics of the decline PL until graduating seventh grade, common for students of both sexes. In the eighth grade, the level of PL increased slightly among boys and girls, but the indexes of PL among girls were higher throughout the school year (2777,8 and 2596,2\%o among girls, vs. 2631,6 and $2333,3 \%$ among boys). During the ninth grade, girls' PL levels increased and almost did not change among boys. Thus, peak waves of pathological lesion should become the point of application of preventive efforts. The analysis of pathological lesions also allows determining the critical periods for the manifestation of diseases of individual groups. Thus, in our study, the most critical period for elementary school students was the sixth grade, when the highest PL indexes took place in these five disease classes: endocrine system, eating disorders; diseases of the musculoskeletal and urogenital systems, disorders of the psyche and behavior, diseases of the eye and and adnexa. For girls, the periods with the highest PL indexes were sixth grade (the highest prevalence of eye and adnexa diseases, respiratory system, and musculoskeletal disorders) and theeighth grade with the highest PL indexes in desiases of digestive system, urogenital system, disorders of the psyche and behavior. That is, health monitoring data enables the introduction of preventive initiatives, taking into account age and gender characteristics, which is crucial for the effectiveness of interventions. When non-communicable pathologies are spread, the health care system must be focused on preventative measures, and the effectiveness of these measures depends on the precise identification of problematic issues for the development of prevention programs. According to $\mathrm{WHO}$, health is mostly correlated with a lifestyle where behavioral factors such as unhealthy eating, low physical activity, tobacco and alcohol use have the most negative effects. Other social determinants of health formation, micro- and macro-social factors, which, among other things, shape worldview and behavior, are also of great importance $[2,3]$.

Identification of important social factors, factors that influence the formation of health of modern adolescents and determine their life values, identify the risks of deterioration of their health, contribute to the development of targeted prevention programs aimed at shaping the health behavior of modern adolescents. Based on a survey of students, it is possible to obtain information on their adherence to the daily regimen, nutritional status, health behaviors, as well as information on the need for schoolchildren to know the 
factors that shape health with the further development of preventive measures. Thus, according to the experts of the State Institution «Institute of Health Protection of Children and Adolescents of NAMS of Ukraine» it is determined that the main reason that hinders a healthy lifestyle is indicated by "lack of time" (49,3\%) and "laziness" (32,2\%), which indicates an inadequate organization of free time and an unconscious attitude to health. The problem that needs to be corrected is the non-compliance with the regime's timetables, the lack of interest in health information and health preserving behavior (only $27,0 \%$ of students read special editions); "tensed" or "unsatisfaying" situationin the family $(23,8 \%)$. Today, parents have lost control of their children's sleeping patterns lack of control over the length of night sleep, multipleness of meals, homework time, or amount of time spent beneath computer. Such studies allow to develop diagnostic tools which determine the factors thathave negative affect of medico-social factors on the health and health-oriented behavior of students. Thus, further analysis of the questionnaire data using the method of S. Kulbak in the modification of A. Genkin and E. Gubler allowed to calculate the diagnostic coefficients (DC) of the informative nature of various medical and social factors. Thus, the factors that maximally adversely affect health and health-oriented behavior (with a high DC that has a negative impact) include such medico-social factors as: the fact of smoking of all family members; dissatisfaction with the relationship in the family or a tense situation in it; if a schoolkid does not adhere to a healthy lifestyle or health is the main reason for his/her non-compliance; if they are keen on a show business leaders or have a positive attitude to low alcohol advertising. Poor self-assessment of healthy lifestyle knowledge also becomes a negative factor; the lack of desire or opportunity for physical education, visiting to sports sections is also significant. Low levels of physical activity ( 1 hour per week), less than 6 hours of nighttime sleep and nutrition, preferably once a day also show high negative effects.

In the context of reforming the educational and medical sectors, a clear vision of the health care system for children in general secondary education settings is needed. Therefore, in order to determine the real opportunities and needs for different types of medical care for students in educational settings, including preventive orientation, a survey was conducted: teachers, heads of educational establishments or their deputies, health care providers of medical assistance to students in educational institutions in different areas of Ukraine.

In conditions of overwhelming absence of licenses for conducting medical activity in educational establishments, preventive work can and should become the main type of work of medical workers in schools. Due to the change of subordination of medical workers to the Ministry of Education and Science of Ukraine, it is the educators who will influence the updating of the functional duties of medical workers of educational institutions, formation of new skills and competences.

According to the survey, the collaboration of health professionals and the teaching staff in educational insti- tutions is generally effective. For example, according to educators and health professionals among the important sections of the workin volvement of a health care worker were identified: working with parents on health issues, conducting anti-epidemic measures, monitoring nutrition and providing emergency care.

Some discrepancies were related to physical education control and health monitoring, to which health care providers paid less attention due to the expansion of primary care physicians.

Principals and educators, in comparison with medical professionals, pay less attention to carrying out in the institution of medical and rehabilitation work with schoolchildren: outpatient admission and carrying out of health measures in the conditions of educational institution, which may be caused by the absence of legislative documents on medical practice.

The existing system of medical support for schoolchildren can be reflected in parents' assessment. The definition of parents' vision of certain in-demand medical care for their children at school became important.

According to the survey, it is determined thatin general parents are satisfied with medical care in the educational setting; the share of schoolchildren who refer to a healthcare provider during the school year is about $60,0 \%$. On the part of parents, the most demanded types of medical care in educational institutions are: assistance in the treatment of a child with complaints $(82,2 \%)$, obtaining qualified assistance in the event of urgent conditions $(36,6 \%)$, vaccination (34,7\%). Unfortunately, parents do not pay much attention to the importance of preventive work. According to surveyonly $27,2 \%$ of parents are demanding it in schools. That is, when parents give their childs under care of educational institution, they expect providing out patient care to the child if needed, which slightly differs from the opinion of the principals.

Thus, the analysis of the results of monitoring the health of children, determining the risk factors for its deterioration, outlining the requirements for medical assistance from consumers of school medical services, taking into account the needs and value orientations of the students themselves become the basis for the development of purposeful preventive measures at the educational institution or among educational staff. And all this is possible only with the establishment of a clear system of medical care for children in educational institutions, which will facilitate interaction with health care institutions and ensure the effective functioning of the educational institution.

Therefore, in the current conditions of transformation of the education system and the medical sector due to the imperfection of the regulatory framework on the background of further deterioration of children's health, it is urgent to develop the Concept of health care for children in educational settings, which aims to prevent the spread of non-communicable pathology, development of skills health-oriented behavior.

Problems that need solving nowadays are:

- lack of a clear up-to-date legal framework on the provision of medical assistance to children in terms of educational 
institutions, competences and volumes of medical care; - the functioning of a system of monitoring the health of educational groups in an educational institution, control of epidemiological situation in an educational institution is not coordinated; identifying risky forms or addictive behaviors among children and adolescents;

- lack of an algorithm for the development and implementation of timely effective and appropriate prevention programs aimed on improving level of health and health-oriented behavior of student youth;

- lack of information system for accounting data on the relationship between the dynamics of health and the effectiveness of preventive measures;

- crisis of the system of professional and competence development for specialists providing medical care to children in educational institutions;

- lack of effective algorithm for intersectoral interaction of specialists who provide medical, prophylactic or medical rehabilitation assistance to students of general secondary educational institutions.

To address these issues, consider the following Conceptual Guidelines for Children's Health Care in Institutions.

Conceptual Guideline 1. Improvement of the system of medical support for children and students in conditions of educational institutions, establishment of medical support for professional self-determination of adolescents, preparation of young men for military service.

Ways of implementation should include:

1. Improvement of the legal support for the health care of children and adolescents, taking into account the existing national legal framework, updating the documents on ensuring the sanitary and hygienic well-being of the conditionsoflearning;

2. Setting at the legislative level the main structure that should coordinate the activities of school health systems;

3. Improvement of functional duties and competencies of medical workers providing medical assistance in educational institutions, defining ways of their interaction and subordination with other structures and organizations, including issues of medical support of professional self-determination of teenagers, preparation of young men for military service;

4. Updating normative documents on logistical and medical equipment of medical offices of institutions of general secondary education, observance of sanitary and hygienic requirements;

5. Outlining the authority of the medical worker of the educational institution regarding his participation in planning educational activities for the formation of HLS of students, work with parents, participation of the medical worker in these activities, their multiplicity;

6. Determining the feasibility and appropriateness of conducting rehabilitation measures for children with chronic pathology or special medical needs in institutions of general secondary education.

Conceptual Guideline II. Prevention of the prevalence of non-communicable pathology, formation of health preserving behavior of children. Ensuring the sanitary and hygienic well-being of educational institutions.
Measures to guide on:

1. Strengthening health workforce to ensure the effective functioning of medical support children in learning groups; provide an up-to-date algorithm for upgrading their skills and competences;

2. Provide a general health care system for children and students with a team of specialists of the following profiles: pediatricians, adolescent therapists, public health specialists, dietitians, psychologists; social workers; nurses; 3. Provide the capacity of health facilities and vertical structure (at subnational, national and regional levels) to effectively guide and coordinate the health care system of children and adolescents who are enrolled; to define clearly their structural subordination, reporting and communication;

4. Establish a system of monitoring, cross-sectoral interaction for the provision of highly effective medical and preventive care;

5. Introduce strategic planning for healthy lifestyle activities (HLS) with all stakeholders involved;

6. Define standards for assessing the quality of the health care system for children in educational settings, introduce their use (based on the standards proposed by WHO's ERB "European concept of quality standards for school medical services and competencies for school health professionals", development of tools for assessing the quality of care).

The expected results of the implementation of the Conceptual areas of health care for children in educational instituions, takingin to account the European experience, are promotion of a significant increase in the efficiency, quality and accessibility of medical care for school-age children,reduce of the prevalence of diseases among the child population, reduce of the prevalence of behaviorally-oriented health risk factors. Advantages of realization of Conceptual directions:

- optimization of the personnel component of the medical aid system in the conditions of educational institutions; - coverage of student youth;

- building a clear vertical of subordination and functions to achieve student youth health goals;

- optimizing the health monitoring system and the prevalence of disruptive behavior among children and adolescents, improving the effectiveness of prevention-oriented activities and programs;

- defining the procedure for upgrading the qualification and competencies of medical professionals in educational institutions;

- improvement of the system of intersectoral communication.

\section{CONCLUSIONS}

The formation and preservation of the health of the child population is now a problem for both education and health systems. It is appropriate to create and implement school health care measures to ensure that health care is provided to students in educational settings, to prevent the spread of noncommunicable diseases and to develop healthy lifestyle skills.

In the context of global change in the country, it is important not to lose some important aspects of children's 
health, such as health monitoring, assessing the impact of social determinants, coordinated cross-sectoral interaction to prevent the spread of non-communicable diseases among student youth and developing their health skills oriented behavior.

This is the basis for the creation of a clear system of medical care for children in educational institutions, which is based on the improvement of the legal framework, optimization of the personnel component, establishment of intersectoral interaction, definition of a clear system of monitoring of the health of schoolchildren taking into account the needs and opportunities.

\section{REFERENCES}

1. Center for Medical Statistics of the Ministry of Health of Ukraine. URL: https://moz.gov.ua/article/statistic/centr-medichnoi-statistiki-mozukraini.

2. WHO. Situation of child and adolescent health in Europe (2018). URL: http://www.euro.who.int/en/health-topics/Life-stages/childand-adolescent-health/publications/2018/situation-of-child-andadolescent-health-in-europe-2018.

3. WHO. Health Behaviour in School-aged Children (HBSC). URL: http://www.euro.who.int/en/health-topics/Life-stages/child-andadolescent-health/health-behaviour-in-school-aged-children-hbsc.

The article is the result of the research carried out by research work "To study the medico-social conditions of positive influence offamily on preservation and promotion of health of school-age children"
(2017 - 2019), which was performed within the state order of the State Institution "Institute for children and adolescents health care of the National Academy of Medical Sciences of Ukraine".

\section{ORCID and contributorship:}

Heogii M. Danylenko - 0000-0001-7086-2720 A,F

Tetiana V. Peresypkina - 0000-0003-3408-1091 A,C,D

Antonina I. Butenko - 0000-0002-0716-496X ${ }^{B, C}$

Anna M. Peresypkina - 0000-0003-2829-9860 ${ }^{B, E}$

Halyna I. Holubnycha - 0000-0001-7832-2091 B,C

Andrii M. Zinchuk - 0000-0001-7086-2720 C,E

Olha G. Zinchuk - 0000-0001-6777-2302 C,E

\section{Conflict of interest:}

The Authors declare no conflict of interest.

\section{CORRESPONDING AUTHOR}

\section{Tetiana V. Peresypkina}

State Institution "Institute for children and adolescents health care of the National Academy of Medical Sciences of Ukraine"

Av. Ubileyniy, 52-A, Kharkiv, Ukraine

tel: +380506898765

e-mail: tatyanaiozdp@gmail.com

Received: 27.02 .2020

Accepted: 05.05 .2020 